\title{
Optimasi Kinerja Primitive Root Diffuser (PRD) dengan Teknik Sisipan Resonator Jamak
}

\author{
Fahrudin Ahmad, Harjana, Suparmi, Iwan Yahya* \\ LAB RISET AKUSTIK (IARG) - JURUSAN FISIKA FMIPA \\ UNIVERSITAS SEBELAS MARET \\ Jl. Ir. Sutami 36A Kentingan, Surakarta 57126 \\ *E-mail: iwanyy@yahoo.com
}

\begin{abstract}
Abstrak - Telah dilakukan kajian untuk meningkatkan kinerja primitive roots diffuser (PRD) dengan model standar berbentuk Skyline dengan jumlah elemen 5x8. Teknik modifikasi yang telah diterapkan adalah penyisipan rangkaian resonator seperempat panjang gelombang dengan kedalaman yang bersesuaian dengan masing-masing elemen PRD. Pengujian dilaksanakan dengan metode interrupted noise mengacu kepada prosedur standar ISO 3382 untuk mendapatkan nilai waktu dengung $T_{30}$ dan $T_{20}$. Adapun respon spasial dari PRD yang dikembangkan disimulasikan dengan perangkat lunak AFMG Reflex. Hasil pengujian menunjukkan bahwa penambahan rangkaian resonator jamak berhasil mengurangi nilai waktu dengung rerata sebesar 0,78 dan 1,83 sekon berturut-turut untuk $T_{30}$ dan $T_{20}$ pada bentang frekuensi rendah. Di samping itu pemakaian resonator memperbaiki respon spasial omnidireksional PRD.
\end{abstract}

Kata kunci:PRD, Skyline, waktu dengung, respon spasial

Abstract - The improve performance of primitive roots diffuser (PRD) with the standard model Skyline shaped by the number of $5 \times 8$ elements. Modification technique that has been applied is the insertion of a quarter-wavelength resonator circuit with depth corresponding to each element of the PRD. Theb The method of interrupted noise refers to the ISO 3382 standard procedures to obtain the value of reverberation time T30 and T20. The spatial response of PRD developed simulated with software AFMG Reflex. The results that the addition of resonator to reduce reverberation time average value of 0.78 and 1.83 the T3O and T20 in the low frequency. In addition, the use resonator improved spatial response of omnidirectional of PRD.

Keywords: PRD, Skyline, reverberation time, the spatial response

\section{PENDAHULUAN}

Pemakaian diffuser untuk maksud peningkatan kualitas akustik ruangan telah berlangsung dalam waktu relatif lama khususnya untuk pengendalian bunyi di frekuensi rendah. Prinsip kerja diffuser berkaitan dengan reduksi fraksi energi gelombang yang dipantulkan secara spekular akibat adanya sebagian energi bunyi yang dihamburkan oleh permukaan benda.

Diffuser mempunyai fungsi yaitu menghamburkan gelombang bunyi dan tidak menghilangkan energi bunyi. Diffuser berasal dari kata diffuse mempunyai arti yaitu hamburan.Hamburan suara ini terjadi dalam ruang, sehingga ruangan tersebut mempunyai sifat dan ciri akustik yang distribusi bunyinya merata.[1]

Paper ini menyajikan hasil dari modifikasi desain yang berbeda yakni pengaruh sisipan resonator jamak seperempat panjang gelombang terhadap pengujian waktu dengung dengan kinerja serapan bunyi elemen diffuser. Pilihan pada pemakaian resonator jamak didasarkan pertimbangan fungsional dari rancangan yang dikembangkan. [2]

\section{LANDASAN TEORI}

\section{Diffuser}

Diffuser merupakan material akustik yang digunakan untuk memperbaiki penyimpangan suara dalam ruangan seperti gema. Di bandingkan dengan menggunakan dinding pemantul yang menyebabkan sebagian besar energi dipantulkan pada sudut yang sama dengan sudut datang, diffuser akan menyebabkan energi bunyi akan terpancar ke berbagai arah, sehingga membuat ruangan lebih difusif.[3]

Bunyi yang mengenai permukaan diffuser akan terpantul dari dasar sumur dan akhirnya terpantul kembali ke ruang. Hal ini dapat dianggap bahwa tidak ada energi yang hilang pada diffuser, karena semua bunyi yang datang akan dipantulkan kembali ke ruang. Semua gelombang bunyi yang terpantul ini memiliki jumlah energi yang sama tetapi fasenya berbeda. Hal ini dikarenakan perbedaan jarak yang ditempuh tiap gelombang bunyi mengenai bagian-bagian dari diffuser yang berbeda-beda. Dengan demiki-an agar hamburan dapat terjadi maka pemilihan kedalaman sumur menjadi sesuatu yang penting.[4]

Diffuser QRD adalah diffuser yang berstruktur kaku, terdiri dari kedalaman berbeda dan dipisahkan oleh dinding tipis. Quadratic Residue Diffuser ini juga mempunyai 2 tipe yaitu satu dimensi dan dua dimensi. Diffuser satu dimensi menghamburkan bunyi hanya pada bidang yang tegak lurus dengan sumur sedangkan dua dimensi menghamburkan bunyi datang ke berbagai arah.[5]

Tabel 1. Kedalaman Quadratic Residue Diffuser 


\begin{tabular}{|l|l|l|l|l|l|l|l|l|l|l|}
\hline 4 & 6 & 3 & 2 & 3 & 6 & 4 & 4 & 6 & 3 & 2 \\
\hline 6 & 1 & 5 & 4 & 5 & 1 & 6 & 6 & 1 & 5 & 4 \\
\hline 3 & 5 & 2 & 1 & 2 & 5 & 3 & 3 & 5 & 2 & 1 \\
\hline 2 & 4 & 1 & 0 & 1 & 4 & 2 & 2 & 4 & 1 & 0 \\
\hline 3 & 5 & 2 & 1 & 2 & 5 & 3 & 3 & 5 & 2 & 1 \\
\hline 6 & 1 & 5 & 4 & 5 & 1 & 6 & 6 & 6 & 1 & 5 \\
\hline 4 & 6 & 3 & 2 & 3 & 6 & 4 & 4 & 4 & 6 & 3 \\
\hline 4 & 6 & 3 & 2 & 3 & 6 & 4 & 4 & 6 & 3 & 2 \\
\hline
\end{tabular}

Pada Quadratic Residue Diffuser (QRD) cara menentukan kedalaman difuser dengan menggunakan Tabel (1).

Sedangkan untuk menentukan panjang dari elemen diffuser (QRD) ini yang ada pada teori dengan lambang Sn dapat mengikuti persamaan berikut ini (Cox and D'Antonio, 2004):

$$
S n=n^{2} \bmod N
$$

dengan $n=0,1,2,3, \ldots . . N-1$ dan $N$ adalah banyaknya sumur (bilangan prima).

Dimana "mod" menunjukkan modulo yaitu sedikitnya sisa yang tidak negatif dan $\mathrm{N}$ adalah pem-bangkit bilangan yang merupakan bilangan pokok dan juga menunjukkan jumlah sumur dalam satu periode. Schroeder diffusers bekerja pada kelipatan bilangan bulat dari desain frekuensi. Desain frekuensi normal diatur pada batas frekuensi

rendah.

Kedalaman sumur diffuser sangat berpengaruh terhadap hamburan gelombang bunyi. Penentuan kedalaman sumur diffuser dengan persamaan sebagai berikut :

$$
d n=\frac{5 n \lambda_{0}}{2 N}
$$

dengan $d n$ yaitu kedalaman per elemen sumur diffuser, $\lambda_{o}$ yaitu merupakan kecepatan bunyi di udara dalam keadaan normal.

Lebar sumur diffuser $(w)$ berpengaruh terhadap frekuensi gelombang bunyi yang akan dihamburkan. Lebar sumur diffuser dengan persamaan berikut:

$$
w=\frac{1}{2} \lambda_{\text {min }}
$$

dengan $\lambda_{m i n}$ adalah panjang gelombang minimum dan $w$ adalah lebar sumur. Di kaitkan dengan panjang gelombang $\lambda$ dapat diperoleh persamaan :

$$
\lambda=\frac{v}{f}
$$

dengan $v$ adalah kecepatan bunyi di udara dan $f$ adalah frekuensi desain.

Ragam diffuser telah berkembang pesat. Modifikasi permukaan umumnya menjadi teknik yang dipilih untuk tujuan optimasi kinerja serapan. [6]

Hal baru yang dilakukan dalam penelitian ini adalah memberi lubang pada permukaan diffuser yang digunakan untuk modifikasi permukaan diffuser. Hal ini merujuk pada penelitian terdahulu yang dilakukan oleh [6] bahwa multiHelmholtz resonator memberikan efek yang baik bagi pengurangan bising dan dapat meningkatkan bandwith penyerapan.

\section{Waktu Dengung}

Waktu dengung adalah wak-tu yang diperlukan oleh bunyi untuk berkurang $60 \mathrm{~dB}$, dihitung dalam detik. Setiap ruangan mem-butuhkan waktu dengung berbeda-beda tergantung dari pengguna-annya. Waktu dengung yang terlalu pendek akan menyebabkan ruangan mati, sebaliknya waktu dengung yang panjang akan memberikan su-asana hidup pada ruangan. [8]

Reverberatoin time dapat dihitung dari data ruangan yang diketahui persamaan :

$$
R T=\frac{0,16 \mathrm{~V}}{A}
$$

Dimana:

$$
\begin{array}{ll}
\text { RT } & \text { : waktu dengung }(\mathrm{s}) \\
\text { V } & \text { : volume ruang }\left(m^{5}\right) \\
\text { A } & \text { : penyerapan ruang total (sabin) }
\end{array}
$$

Persamaan (5) dikenal dengan teori klasik Sabine. Penyerapan suatu permukaan diperoleh dengan mengalikan luasnya $\mathrm{S}$ dengan koefisien penyerapan $\alpha$ dan penye-rapan total $\mathrm{A}$ diperoleh dengan menjumlahkan perkalian ini deng-an menyertakan penyerapan yang dilakukan oleh orang dan benda-benda lain dalam ruang (tempat duduk, karpet, tirai, dan lain - lain), dan digunakan rumus :

$$
A=S_{l} \alpha_{1}+S_{2} \alpha_{2}+S_{3} \alpha_{3}+\ldots+S_{n} \alpha_{n}
$$

Dengan $\quad$ S1 $\quad \ldots \quad$ Sn adalah luas masing-masing permukaan dalam $m^{2}$ dan $\propto_{1} \quad \ldots \propto_{n}$ adalah koefisien penyerapannya masing - masing. [9]

\section{METODE PENELITIAN/EKSPERIMEN}

\section{A. Alat yang digunakan}

Peralatan yang digunakan pada pengukuran ini antara lain :

i. $\quad B \& K$ Power Amplifier Type 2734 digunakan untuk menguatkan gelombang bunyi.

ii. B\&K Sound Source Omni Power Type 4292 digunakan untuk pembangkit bunyi berupa random noise.

iii. $\quad B \& K$ Hand-Held Analyzer Type 2270 digunakan untuk merekam bunyi / data pada frekuensi tertentu.

iv. Software BZ 5503 Utility Software for Hand Held Analyzer Pulse Refluk

v. Laptop

vi. Tripod berfungsi sebagai dudukan Sound Source Omni Power dan Hand-Held Analyzer.

\section{B. Perancangan dan Pembuatan Diffuser}

1. Pembuatan Model Elemen Diffuser

Model elemen diffuser disajikan dalam Gambar 2. Dalam hal ini elemen pada QRD standar dimo-difikasi menjadi resonator. Dengan demikian, konfigurasi dasar QRD dengan satu elemen berubah menjadi QRD termodifikasi dengan tiga elemen dimana elemen terkecuali pada elemen posisi maksimal $\{0\}$. Gambar 3.b menjelaskan bahwa sisipan resonator jamak pada tiap elemen kecuali elemen yang bernilai maksimal, sehingga PRD berubah menjadi N:30.

Elemen diffuser dibuat dari bahan Styrofoam dengan ketebalan $3 \mathrm{~cm}$. Spesifikasi elemen diffuser yang digunakan 
dalam penelitian adalah sebagai berikut. Konfigurasi resonator jamak dan sumur diffuser standar yang membentuk diffuser termodifikasi dengan elemen berukuran $8 \mathrm{~cm} \times 8$ $\mathrm{cm}$ berbentuk persegi dengan ukuran panjang dan lebar bantalan papan diffuser $40 \mathrm{~cm}$ dan $64 \mathrm{~cm}$. Diameter lubang resonator $3 \mathrm{~cm}$, sementara sumur diffusernya sendiri memiliki jari-jari $4 \mathrm{~cm}$.

2. Model Modifikasi QRD

Model yang digunakan dalam penelitian ini berupa struktur QRD dengan jumlah elemen $\mathrm{N}=30$ yang dibentuk dari konfigurasi perulangan pola enam buah diffuser sejenis dengan $\mathrm{N}=11$ sehingga diperoleh urutan kedalaman sumur diffuser adalah $\{46323644632\}$.

Lebar elemen sumur diffuser adalah $8 \mathrm{~cm}$, sementara resonator yang disisipkan memiliki diameter $3 \mathrm{~cm}$ dengan kedalaman yang berbeda. Rancangannya disajikan pada Gambar 3.b.

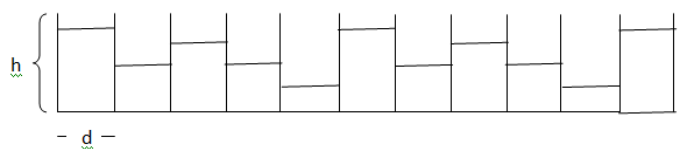

(a)

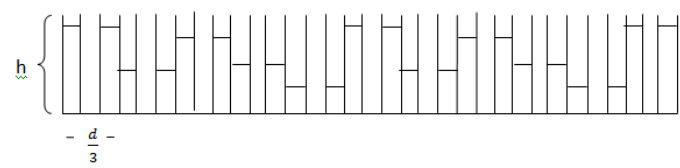

Gambar (1). Struktur diffuser yang digunakan dalam penelitian, (a) kon-figurasi standar PRD N:11 tanpa sisipan Resonator, (b) diffuser dengan sisipan resonator jamak pada tiap elemen kecuali elemen yang bernilai maksimal, sehingga PRD berubah menjadi N:30.

Gambar (1b) diatas adalah modifikasi QRD, dimana untuk menentukan panjang dari elemen diffuser (QRD) ini dapat mengikuti persamaan (1).

Sedangkan untuk penentuan kedalaman sumur diffuser modifikasi digunakan persamaan (2) tetapi dengan mengalikan matriks [h,0,h] sebagai berikut :

$$
d n=\frac{5 \times \lambda_{0}}{2 N}[\mathrm{~h}, 0, \mathrm{~h}]
$$

dengan (0) adalah maximum depth, sedangkan $d n$ adalah kedalaman per elemen sumur diffuser, $\lambda_{o}$ yaitu merupakan kecepatan bunyi di udara dalam keadaan normal.

Dari uraian diatas dapat diketahui bahwa pengkalian matriks $[\mathrm{h}, 0, \mathrm{~h}]$ merupakan formula baru untuk menghitung kedalaman per elemen sumur diffuser untuk QRD modifikasi pada penelitian ini.

C. Skema Pengujian

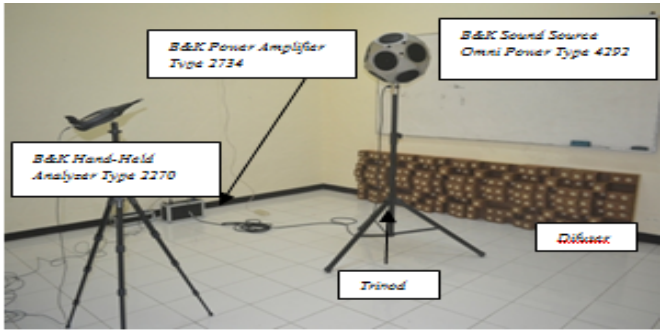

Gambar (2). Skema Pengujian Difusser

Hasil dari pengujian disajikan pada grafik menggunakan perangkat lunak Origin versi 8.0. Dengan menggunakan software Software BZ 5503 Utility Software for Hand Held Analyzer Pulse Refluk kemudian dilakukan analisis terhadap koefisien serap pada orientasi sudut sebesar $0^{\circ}$ dan $180^{\circ}$ terhadap sumber bunyi pada frekuensi $20 \mathrm{~Hz}-6.300 \mathrm{~Hz}$.

\section{HASIL DAN PEMBAHASAN}

Nilai koefisien serapan elemen diffuser disajikan pada Grafik 4.1 dan 4.2. Dalam hal ini terdapat kondisi pengujian yang berbeda berkait dengan penempatan resonator pada konstruksi diffuser.

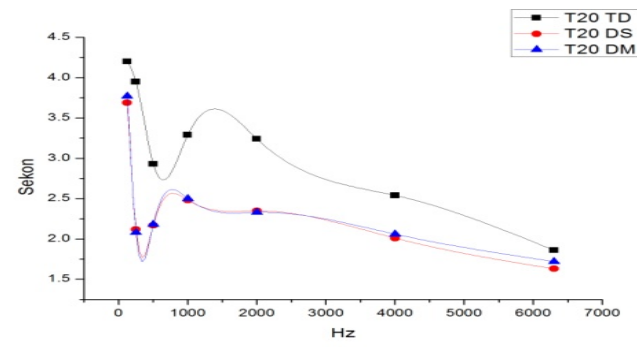

Grafik (1). Hubungan $T_{20}$ pada pengujian pada ruangan tanpa diffuser,diffuser standart, dan diffuser modifikasi pada orientasi $0^{\circ}$.

Pada Grafik (1) di atas adalah grafik hubungan antara koe-fisien serapan bunyi $\left(T_{20}\right)$ terhadap frekuensi dengan variasi perlakuan pengujian diffuser pada orientasi $180^{\circ}$.

Nilai koefisien serapan bunyi lebih dari 2,93 sekon pada ruangan tanpa diffuser terjadi pada bentang frekuensi 500-1000 Hz. Pada diffuser standar nilai koefisien serapan bunyi lebih besar dari 2 sekon terjadi pada bentang frekuensi 250-500 $\mathrm{Hz}$ dan untuk diffuser modifikasi nilai koefisien serapan bunyi lebih kecil dari 2,08 sekon terjadi pada bentang frekuensi $250-500 \mathrm{~Hz}$.

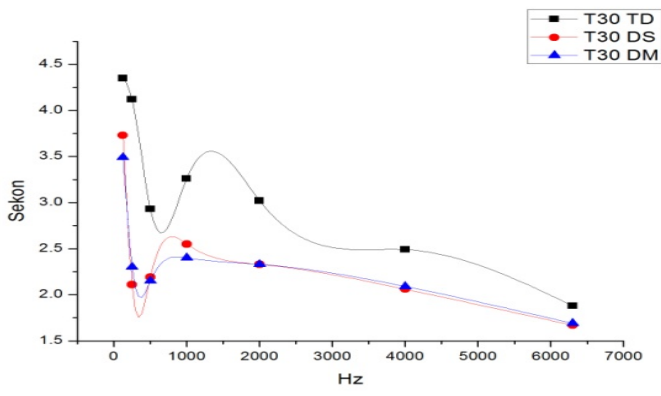

Grafik (2). Hubungan $T_{30}$ pada pengujian pada ruangan tanpa diffuser,diffuser standart, dan diffuser modifikasi pada orientasi $0^{*}$.

Pada Grafik (2) di atas adalah grafik hubungan antara koefisien serapan bunyi $T_{30}$ terhadap frekuensi dengan variasi perlakuan pengujian diffuser pada orientasi $180^{\circ}$. 
Nilai koefisien serapan bunyi lebih dari 2,93 sekon pada ruangan tanpa diffuser terjadi pada bentang frekuensi 500-1000 Hz. Pada diffuser standar nilai koefisien serapan bunyi lebih besar dari 2,11 sekon terjadi pada bentang frekuensi $250-500 \mathrm{~Hz}$ dan untuk diffuser modifikasi nilai koefisien serapan bunyi lebih kecil dari 2,15 sekon terjadi pada bentang freku-ensi 250$500 \mathrm{~Hz}$.

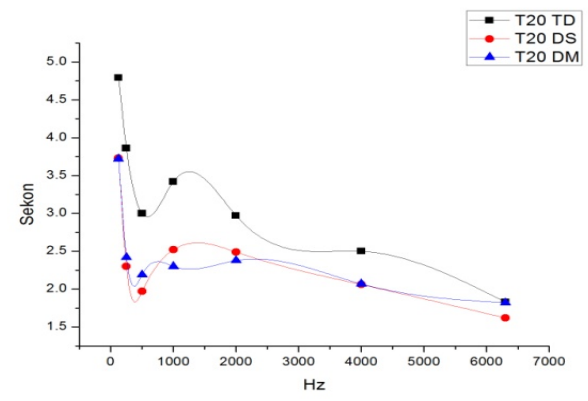

Grafik (3). Hubungan $T_{22}$ pada pengujian pada ruangan tanpa diffuser,diffuser standart, dan diffuser modifikasi pada orientasi $180^{\circ}$.

Pada Grafik (3) di atas adalah grafik hubungan antara koe-fisien serapan bunyi $\left(T_{20}\right)$ terhadap frekuensi dengan variasi perlakuan pengujian diffuser pada orientasi $180^{\circ}$.

Nilai koefisien serapan bunyi lebih dari 3 sekon pada ruangan tanpa diffuser terjadi pada bentang frekuensi 250-1000 Hz. Pada diffuser standar nilai koefisien serapan bunyi lebih besar dari 1,97 sekon terjadi pada bentang frekuensi $250-500 \mathrm{~Hz}$ dan untuk diffuser modifikasi nilai koefisien serapan bunyi lebih kecil dari 2,17 sekon terjadi pada bentang frekuensi 250-500 $\mathrm{Hz}$.

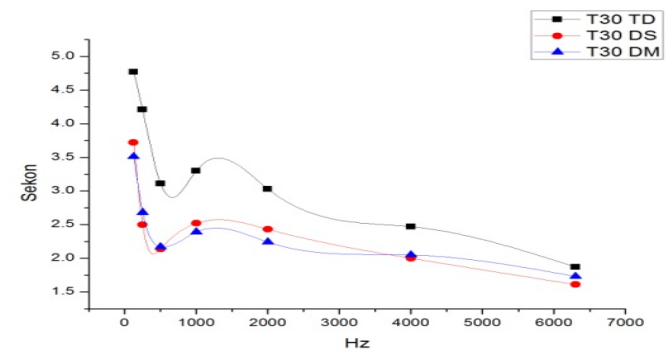

Grafik (4). Hubungan $T_{32}$ pada pengujian pada ruangan tanpa diffuser,diffuser standart, dan diffuser modifikasi pada orientasi $180^{\circ}$.

Pada Grafik (4) di atas adalah grafik hubungan antara koe-fisien serapan bunyi $\left(T_{30}\right)$ terhadap frekuensi dengan variasi perlakuan pengujian diffuser pada orientasi $180^{*}$.

Nilai koefisien serapan bunyi lebih dari 3,11 sekon pada ruangan tanpa diffuser terjadi pada bentang frekuensi 500-1000 Hz. Pada diffuser standar nilai koefisien serapan bunyi lebih besar dari 2,14 sekon terjadi pada bentang frekuensi 250-1000 $\mathrm{Hz}$ dan untuk diffuser modifikasi nilai koefisien serapan bunyi lebih kecil dari 2,17 sekon terjadi pada bentang frekuensi $250-500$ Hz.

Dari uraian keterangan grafik diatas menunjukkan bahwa modifikasi diffuser dengan resonator jamak memberikan dampak yang signifikan pada perubahan serapan di frekuensi rendah pada bentang yang lebih kecil dari $600 \mathrm{~Hz}$. Hal ini disebabkan karena perubahan volume yang signifikan yang dapat dapat memicu mekanisme resonansi di frekuensi rendah.

Sehingga, diffuser merupakan komponen material akustik yang sangat penting digunakan untuk memperbaiki penyimpangan suara dalam ruangan seperti gema. Di bandingkan dengan menggunakan dinding pemantul yang menyebab-kan sebagian besar energi dipan-tulkan pada sudut yang sama de-ngan sudut datang, penggunaan diffuser akan menyebabkan energi bunyi akan terpancar ke berbagai arah, sehingga membuat ruangan lebih difusif.

\section{KESIMPULAN}

Berdasarkan hasil pengujian di laboratorium terhadap elemen diffuser yang dikembangkan, dapat disimpulkan bahwa teknik sisipan resonator jamak dapat memberikan peningkatan kinerja serapan yang bersifat akumulatif dan signifikan serta pada saat yang bersamaan dapat memunculkan respon spasial omni-directional yang baik pada bentang frekuensi rendah. Dengan demikian dapat di simpulkan bahwa rancangan diffuser dengan sisipan resonator jamak memiliki potensi yang baik untuk aplikasi pada kondisi dimana terdapat bising yang diakibatkan oleh mesin, kendaraan, atau peralatan industri maupun peralatan elektronik yang dapat menimbulkan kebisingan.

Berdasarkan hasil penelitian modifikasi penempatan resonator jamak pada konstruksi diffuser mempengaruhi nilai koefisien sera-pan bunyi pada frekuensi tertentu. Pada frekuensi rendah diffuser modifikasi mempunyai nilai koefisien serapan bunyi lebih baik daripada diffuser standar.

\section{PUSTAKA}

Buku:

[1] Leslie L, Doelle \& Dra. Lea Prasetio, M.Sc..Akustik Lingkungan. Mc Graw-Hill Book Company:New York, 1972.

Buku kompilasi makalah (edited book):

[2] Zhang, R., Gu, H., Hu, Y., and Xia, S. 2010. Investigation on Multi-Helmholtz Resonator in the Discharge System of Rotary Compressor. International Compressor Engineering Conference. Paper 1954.

Buku:

[3] Cox, T. J. and D'Antonio, P.. Acoustic Absorbers and Diffusers - Theory, design and application. Spon Press, London and New York, 2004

[4] Doelle, L. Environmental Acoustics. Mc Graw Hill B.C, New York, 1972.

[5] Negro, F., Cremonini ,C., Properzi, M., and Zanuttini, R. Sound absorption coefficient of perforated plywood: an experimental case study. World Conference on Timber Enginering (WCTE)., 2010.

[6] Werner Hans, S, "More on the diffraction theory of Schroeder diffusors", J. Acoust. Soc. Am, 1981, 70, 633. 
[7] Everest Alton F, Ken. C Pohlmann, Master Handbook of Acoustic, McGraw-Hill, , 2009 : 257-259.

[8] Satwiko, Prasasto, fisika bangunan 2, Edisi 1, Penerbit Ansi .Yogyakarta, , 2004. 